\title{
Pengaruh Oil Sludge Pertamina Surabaya Terhadap Kuat Tekan Keramik Tradisional
}

\author{
Adi Ilcham, Dyah Tri Retno, Alan Syahputra, M. Novie Aprianto \\ Program Studi Teknik Kimia, FTI, UPN "Veteran" Yogyakarta \\ Jl. Lingkar Utara Condong Catur, Sleman, DIY \\ E-mail: adi_ilcham@yahoo.com
}

\begin{abstract}
Oil sludge is the solidifying oils that lying on the open space around the fuel storage tank. Heaps of the waste continues to increase could lead to environmental pollution due to the waste containing heavy metal. This research aims to study the effect of oil sludge on the compressive strength of traditional ceramics within range of sintering temperature (600$\left.1000{ }^{\circ} \mathrm{C}\right)$, sintering time (1-3 hours), and raw material compositions. The experiment begins by mixing the ceramic raw materials. Material was mixed with water and milled using Mortar Hand (milling). A cermic mold was used to get ceramic specimens. The mold dimension is length of $8 \mathrm{~cm}, 4 \mathrm{~cm}$ wide, and $2 \mathrm{~cm}$ high. The specimens were sintered in a furnace at different temperatures and holding time. Finally, the ceramics were observed its compressive strength. The results showed that the waste oil sludge can be involved in the manufacture of traditional ceramics. In the view of the compressive strength, the best conditions for fabricating traditional ceramics are oil sludge of $16.67 \% \mathrm{w}$., sintering temperature of $800{ }^{\circ} \mathrm{C}$, and sintering time of 2.5 hours.
\end{abstract}

Key Words: ceramic, compressive strength, oil sludge, traditional, waste

\section{Pendahuluan}

Kebutuhan energi yang besar, khususnya minyak dan gas menyebabkan Pertamina, meningkatkan aktifitas eksplorasi dan produksinya. Dampak dari peningkatan produksi adalah dihasilkan limbah berupa oil sludge yang mengandung logam berat. Karena alasan biaya yang mahal, limbah ini hanya ditimbun pada gudang-gudang penyimpan limbah milik Pertamina tanpa adanya proses pengolahan yang memadai. Timbunan limbah yang terus akan bertambah, dikhawatirkan dapat menimbulkan pencemaran lingkungan akibat kontaminasi logam berat (wikipedia.org). Oleh karena itu Perlu dilakukan suatu kajian yang bertujuan untuk memanfaatkan limbah oil sludge Pertamina sebagai bahan baku dalam pembuatan keramik tradisional.Keramik adalah campuran atau paduan bahan inorganik dan non metalik yang terikat secara ionik atau kovalen (wikipedia.org). Hasil analisis di awal penelitian menunjukkan bahwa limbah oil sludge Pertamina mengandung unsur-unsur logam berat dan silikat yang dapat dimanfaatkan untuk bahan. Dalam penelitian ini peneliti menggunakan oil sludge Pertamina
Surabaya sebagai salah satu bahan bahan baku keramik tradisional. Pemanfaatan limbah oil sludge Pertamina untuk diolah dari bahan berbahaya dan beracun (B3) menjadi suatu produk material rekayasa adalah sangat menguntungkan. Selain untuk memenuhi kebutuhan keramik tradisional dalam negeri, juga dapat membuka lapangan kerja baru, serta mampu meng-cover ongkos pengolahan limbah yang mahal (wikipedia.org) .Penelitian ini bertujuan untuk mempelajari pengaruh oil sludge terhadap sifat-sifat keramik tradisional dengan variabel suhu $\left(600-1000{ }^{0} \mathrm{C}\right)$, waktu (1-3jam), dan perbandingan komposisi.

\section{Tinjauan Pustaka}

\subsection{Oil Sludg.}

Oil Sludge adalah limbah minyak bumi yang mengandung unsur-unsur logam berat dan silikat. Yang dapat dijadikan bahan baku pembuatan keramik. Hasil analisis kandungan kimia logam berat pada oil sludge dapat dilihat pada tabel Tabel 1(Daulay, 2009).

Tabel 1.Kandungan Oil Sludge Pertamina

\begin{tabular}{ccc}
\hline No & Parameter & $\begin{array}{c}\text { Kandungan } \\
(\mathrm{mg} / \mathrm{ml})\end{array}$ \\
\hline 1 & Arsen (As) & 0,18 \\
2 & Barium (Ba) & 80,73 \\
3 & Boron (B) & 448,64 \\
4 & Chromium (Cr) & 34,69 \\
5 & Cadmium (Cd) & 21,76 \\
6 & Timbal (Pb) & 407,79 \\
7 & Zinkum (Zn) & 142,97 \\
\hline
\end{tabular}


Lazimnya metode pemisahan minyak didalam lumpur dilakukan dengan menambahkan air pada oil sludge tersebut. Oil sludge yang ditambah air, oil akan berbentuk emulsi dengan air dan sludge, hal ini dapat dirusak dengan menggunakan emulsion breaking, yaitu memisahkan emulsi minyak dalam air dan padatan. Emulsi dapat dirusak dengan menambahkan bahan kimia yaitu tawas. Air ditambahkan pada oil sludge dengan perbandingan yang berbeda pada pH 6-7,5. (Nalco,1979)

\subsection{Keramik.}

Kata keramik berasal dari bahasaYunani keramos yang artinya bahan yang dibakar atau barang tembikar (Anderson et al, 1990). Kamus dan ensiklopedi tahun 1950-an mendefinisikan keramik sebagai suatu hasil seni dan teknologi untuk menghasilkan barang dari tanah liat yang dibakar, seperti gerabah, genteng, porselin, dan sebagainya (Wikipedia.org). Saat ini bahan keramik tradisional terutama berasal dari tanah liat (tanah lempung). Definisi pengertian keramik terbaru mencakup semua bahan bukan logam dan inorganik yang ber bentuk padat yang merupakan campuran logam dan non logam dan terikat secara ionik atau kovalen (Sembiring, 1990).

Umumnya senyawa keramik lebih stabil dalam lingkungan termal dan kimia dibandingkan elemennya. Bahan baku keramik yang umum dipakai adalah tanah lempung, kaolin, pasir, kuarsa, dan air. Sifat keramik sangat ditentukan oleh struktur kristal, komposisi dan mineral bawaannya. Oleh karena itu sifat keramik juga tergantung pada lingkungan geologi dimana bahan diperoleh. Secara umum strukturnya sangat rumit sedikit elektron-elektron bebas. Kerangnya beberapa elektron bebas keramik membuat sebagian besar bahan keramik secara kelistrikan bukan merupakan konduktor dan juga menjadi konduktor panas yang jelek.

Pada umumnya keramik memiliki sifat-sifat yang baik yaitu keras, kuat, dan stabil pada temperatur tinggi. Tetapi keramik bersifat getas dan mudah patah seperti halnya pada porselen, keramik cina, atau pun gelas (Surdia dan Saito,1984). Keramik secara umum mempunyai kekuatan tekan lebih baik dibanding kekuatan tariknya.

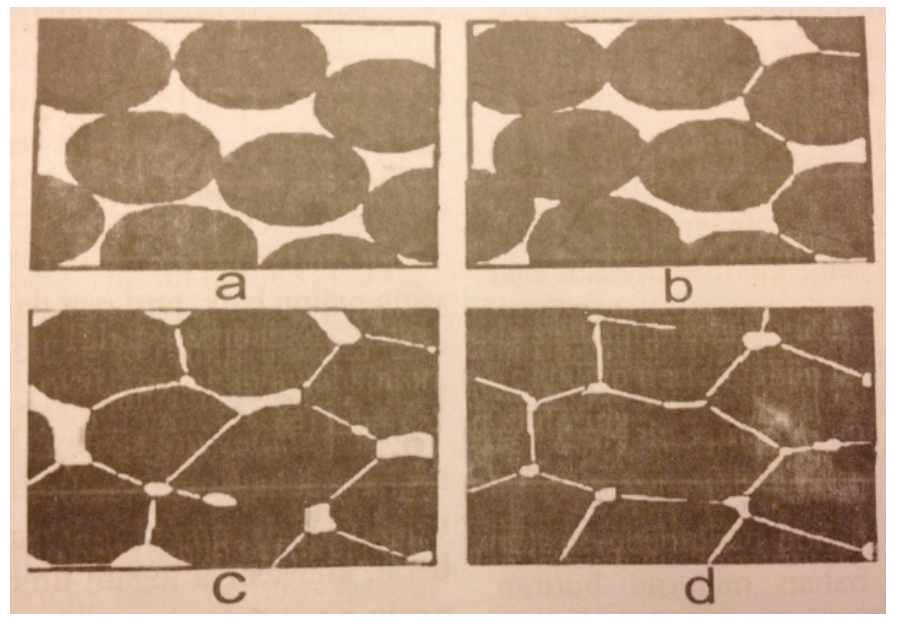

Gambar 1. Tahap perubahan partikel pada saat sintering (Mulder, M., 1996)

(a) Partikel awal, (b) tahap awal sintering, (c) tahap pertengahan sintering, dan (d) tahap akhir sintering

\subsubsection{Klasifikasi Keramik.}

Pada prinsipnya keramik dapat bibagi menjadi dua tipe, yaitu: keramik tradisional dan keramik halus (canggih). Keramik tradisional yaitu keramik yang dibuat dengan menggunakan bahan alam, seperti kuarsa, kaolin, tanah lempung, tanah godean, pasir dan lain-lain. Contoh keramik ini adalah: barang gerabah, guci, patung cina dan keperluan konstruksi untuk industri. Keramik halus (keramik modern atau biasa disebut fine ceramics) adalah keramik yang dibuat dengan menggunakan oksida-oksida logam atau logam, seperti oksida logam $\mathrm{AL}_{2} \mathrm{O}_{3}, \mathrm{ZrO}_{2}$, $\mathrm{MgO}$, dan lain-lain penggunaannya sebagai elemen pemanas, semikonduktor, komponen turbin, dan pada bidang medis.

\subsubsection{Proses Pembuatan Keramik.}

Ada dua proses dasar yang dikembangkan untuk pembentukan keramik. Pertama, menggunakan partikel halus yang dicampur dengan cairan atau pengikat, yang kemudian diproses dengan pembakaran. Dalam hal ini langkah utama adalah penyiapan bahan, pembentukan dan pembakaran. Kedua, melelehkan material menjadi cairan dan kemudian membentuknya selama pendinginan dan pengerasan.

Tahapan proses terbentuknya keramik adalah sebagai berikut: Secara dissosiasi yaitu proses peruraian bahan menjadi penyusun-penyusunnya karena perlakuan panas. Peristiwa ini misalnya: dehidrasi lempung, peruraian karbonat, sulfat, nitrat, oksida-oksida. Berikutnya senyawa-senyawa yang terjadi dari dissosiasi berkaitan menjadi senyawa kompleks. Akhirnya pada sintering atau pembakaran merupakan suatu proses perlakuan panas yang mengubah massa serbuk menjadi massa yang kohesif tanpa terjadi pengembangan massa. Suhu sintering biasanya lebih dari setengah titik leleh material yang disinter. Tujuan sintering yaitu untuk mengurangi porositas padatan (aspdin.wifa.unileipzig, 2008). 
Gambar 1. memperlihatkan tahap perubahan partikel pada saat sintering. Selama tahap awal sintering, terjadi peleburan tanpa penyusutan padatan dan pembentukan leher (necking) yang menghasilkan cekungan. Selama tahap sintering selanjutnya terjadi pertumbuhan leher (necking), pembentukan pori dan dimungkinkan partikelpartikel akan saling mendekat sehingga terjadi penyusutan padatan. Selama tahap akhir sintering tidak terjadi pertumbuhan pori (German, R.M., 1996). Sebelum disinter, material keramik harus terlebih dahulu dicetak. Berbagai proses pencetakan antara lain: dry pressing, slip casting, tape casting, extrusion, injection molding, isostatic, dan rolling.

\subsubsection{Sifat Keramik}

Sifat yang umum dan mudah dilihat secara fisik pada kebanyakan jenis keramik adalah brittle atau rapuh, hal ini dapat dilihat pada keramik jenis tradisional seperti barang gerabah, gelas, kendi, guci, patung cina dan sebagainya. Coba jatuhkan piring yang terbuat dari keramik bandingkan dengan dari logam, pasti keramik mudah pecah, walaupun sifat ini tidak berlaku pada jenis keramik tertentu, terutama jenis keramik hasil sintering dan campuran sintering antara keramik dengan logam Sifat lainnya adalah tahan suhu tinggi.

\subsection{Komposisi Keramik Tradisional}

\subsubsection{Tanah Godean.}

Tanah Godean merupakan mineral tanah yang berasal dari daerah godean yang biasanya berwarna putih. Yang dimana tanah godean terlapisi dengan satu sisi tetrahedral yang dihubungkan melalui atom-atom oksigen ke sisi oktahedral alumina. Batuan yang kaya akan kaolin sebagai tanah cina atau kaolin yang berfungsi sebagai perekat dalam pembuatan keramik tradisional (Industri Keramik Kasongan, 2012).

\subsubsection{Tanah Lempung.}

Lempung atau tanah liat ialah kata umum untuk partikel mineral berkerangka dasar silikat yang berdiameter kurang dari 4 mikrometer. Lempung mengandung leburan silika dan/atau aluminium yang halus. Unsur-unsur ini, silikon, oksigen, dan aluminum adalah unsur yang paling banyak menyusun kerak bumi. Lempung terbentuk dari proses pelapukan batuan silika oleh asam karbonat dan sebagian dihasilkan dari aktivitas panas bumi.

Lempung membentuk gumpalan keras saat kering dan lengket apabila basah terkena air. Sifat ini ditentukan oleh

Percobaan untuk mempelajari pengaruh komposisi oil sludge terhadap kuat tekan keramik hasilnya dapat dilihat pada Tabel 1 . jenis mineral lempung yang mendominasinya. Mineral lempung memiliki sifat elastis yang kuat, menyusut saat kering dan membesar saat basah. Karena perilaku inilah beberapa jenis tanah dapat membentuk kerutan-kerutan atau "pecah-pecah" bila kering. (Wikipedia bahasa Indonesia,ensiklopediabebas.htm).

\subsubsection{Pasir Sungai.}

Pasir Sungai adalah contoh bahan material butiran yang berasal dari sungai. Butiran pasir umumnya berukuran antara 0,0625 sampai 2 milimeter. Materi pembentuk pasir adalah silikon dioksida, tetapi di beberapa sungai umumnya dibentuk dari batu kapur. Pasir tidak dapat di tumbuhi oleh tanaman, karena rongga-rongganya yang besar-besar (Wikipedia bahasa Indonesia,ensiklopediabebas.htm).

\section{Percobaan}

Bahan (tanah liat, tanah godean, pasir, dan oil sludge) yang akan dicampurkan ditimbang dengan neraca analitik. Bahan-bahan dicampur dengan air sebanyak $40 \mathrm{ml}$. Agar homogen bahan dicampur menggunakan Mortar Tangan (penggilingan) dengan 10 kali giling. Bahan kemudian diletakkan pada cetakan berbentuk balok dan ditekan menggunakan beban $150 \mathrm{~kg}$. Cetakan berukuran panjang $8 \mathrm{~cm}$, lebar $4 \mathrm{~cm}$, dan tinggi $2 \mathrm{~cm}$. Hasil cetakan dibiarkan di ruang terbuka tanpa sinar matahari selama 2 hari. Kemudian hasil cetakkan disintering dengan dimasukkan ke dalam furnace. Suhu diatur $\left(600-1000{ }^{\circ} \mathrm{C}\right)$ dan waktu tinggal hasil cetakkan dalam furnace bervariasi antara 1 3 jam. Setelah mencapai suhu dan waktu yang diinginkan furnace dimatikan dan keramik dibiarkan dalam furnace mendingin selama 1 hari dilanjutkan dengan karakterisasi berupa kuat tekan keramik.

Pengukuran kuat tekan sampel keramik yang telah disintering menggunakan Ultimate Testing Machine nomor seri 111105 STDZ-3 Digital

Point Load Tester dengan kecepatan penekanan konstan. Nilai kuat tekan diperoleh dalam satuan Kilo Newton (KN).

\section{IV.Hasil Dan Pembahasan.}

Pengaruh Komposisi Oil Sludge terhadap Kuat Tekan Keramik Tradisional 
Tabel 1. Hasil Data Variabel Komposisi Suhu $900^{\circ} \mathrm{C}$, waktu 2 jam

\begin{tabular}{ccc}
\hline No & Oil Sludge(gr) & Kuat Tekan $(\mathrm{KN})$ \\
\hline 1 & $10,71 \%$ & 11,15 \\
2 & $13,79 \%$ & 12,05 \\
3 & $16,67 \% *$ & 13,45 \\
4 & $19,36 \%$ & 8,65 \\
5 & $21,87 \%$ & 8,05 \\
\hline
\end{tabular}

Dari Tabel 1. terlihat bahwa penggunaan oil sludge yang paling baik terdapat pada nilai komposisi oil sludge sebesar 25 gram $(16,67 \%)$ dengan nilai kuat tekan sebesar 13,45 kilo newton (KN). Jika Komposisi oil sludge > $16,67 \%$ nilai kuat tekannya makin kecil dan bila komposisi oil sludge $<16,67 \%$ nilai kuat tekannya juga

Pengaruh Variasi Suhu Sintering terhadap Kuat Tekan Keramik Tradisional menurun. Hal ini diduga oil sludge yang mengandung logam berat, khususnya logam timbal $(\mathrm{Pb})$ mampu mendukung peran pasir dalam menjaga kestabilan keramik sehingga dapat mengurangi terjadinya kelemahan pada keramik tradisional. akibatnya kuat tekan keramik relatif besar.

Tabel 2. Hasil Data PercobaanVariasi Suhu

\begin{tabular}{ccc} 
No & Suhu $\left({ }^{\circ} \mathrm{C}\right)$ & KuatTekan(KN) \\
\hline 1 & 600 & 9 \\
2 & 700 & 11 \\
3 & 800 & 14,05 \\
4 & 900 & 13,45 \\
5 & 1000 & 8 \\
\hline
\end{tabular}

Dari Tabel 2. terlihat bahwa dengan komposisi oil sludge $=16,67 \%$ suhu optimum terdapat pada $800^{\circ} \mathrm{C}$ dengan nilai kuat tekan sebesar 14,05 KN. Semakin besar suhu sintering ( $\mathrm{T}>800^{\circ} \mathrm{C}$ ) maka nilai kuat tekannya semakin menurun. Hal ini diduga proses sintering keramik tradisional pada suhu lebih dari $800{ }^{\circ} \mathrm{C}$ daya rekat yang ada menjadi berkurang. Pada suhu kurang dari $800{ }^{\circ} \mathrm{C}$ daya rekat belum terbentuk dengan baik. Sehingga nilai kuat tekan keramik yang optimum terdapat pada suhu $800^{\circ} \mathrm{C}$.

Pengaruh Variasi waktu Sintering terhadap Kuat Tekan

Keramik Tradisional:

Tabel 3.Hasil Data Percobaan Variasi

Waktu Penahanan

\begin{tabular}{cclll}
\hline No & Suhu $\left({ }^{0} \mathrm{C}\right)$ & $\begin{array}{l}\text { Waktu } \\
(\text { jam })\end{array}$ & $\begin{array}{l}\text { Kuat } \\
\text { Tekan }(\mathrm{KN})\end{array}$ \\
\hline 1 & 800 & 1 & 12.7 \\
2 & 800 & 1,5 & 13,2 \\
3 & 800 & 2 & 13,8 \\
4 & 800 & 2,5 & 14,15 \\
5 & 800 & 3 & 14,1 \\
\hline
\end{tabular}

Dari hasil percobaan terlihat waktu tinggal terbaik adalah pada 2,5 jam menghasilkan kuat tekan sebesar 14,15 KN dengan komposisi oil sludge $=16,67 \%$.Dari hasil percobaan Tabel 3. terlihat bahwa waktu penahan optimum pada proses sintering (pembakaran) terdapat pada waktu 2,5 jam (150 menit) dengan perbandingan komposisi: tanah liat: tanah godean: pasir: oil sludge $=1$ : $1: 1 / 2: 1 / 2$ dan suhu sintering $800^{\circ} \mathrm{C}$, yang mempunyai nilai kuat tekan terbaik sebesar $14,15 \mathrm{KN}$.
Semakin Lama nya waktu penahanan ( $\mathrm{t}>2,5$ jam) semakin kecil nilai kuat tekannya dan $(\mathrm{t}<2,5$ jam) semakin kecil pula nilai kuat tekannya. Hal ini diduga keramik tradisional yang mengandung tanah liat, tanah godean, pasir dan oil sludge memang tidak dapat bertahan pada waktu yang lama (suhu yang terlalu tinggi $\mathrm{T}>$ $800^{\circ} \mathrm{C}$ ) yang sesuai dengan karakteristik keramik tradisional, dimungkinkan pada keadaan ini padatan, kadar air dan minyak yang terdapat pada keramik tradisional membentuk porositas yang tinggi, sehingga 
pada $\mathrm{T}>800$ sampel keramik tradisional sudah retak dan pecah. Sehingga nilai kuat tekan keramik yang optimum terdapat pada waktu sintering 2,5 jam.

\section{V.Kesimpulan}

Berdasarkan penelitian yang telah dilakukan dapat disimpulkan beberapa hal sebagai berikut.

1. Bahwa limbah oil sludge Pertamina dapat dimanfaatkan sebagai campuran dalam pembuatan keramik tradisional.

2. Oil sludge berpengaruh terhadap kekuatan keramik tradisional. Komposisi optimum bahan baku pada pembuatan keramik tradisionaladalah, tanah liat: tanah godean: pasir: oil sludge $=1: 1: 1 / 2: 1 / 2$ pada suhu $800^{\circ} \mathrm{C}$ selama 2,5 jam diperoleh nilai kuat tekan sebesar 14,15 KN. Hasil kuat tekan ini melebihi nilai kuat tekan dari pembuatan keramik tradisional kasongan pada umumnya.

\section{Daftar Pustaka}

Daulay, A.H. 2009. Pemanfaatan limbah Oil sludge Pertamina sebagai Bahan Baku dalam Pembuatan Keramik Konstruksi, Tesis Pascasarjana Universitas Sumatra Utara, Medan.

Anderson, J.C., Leaver, K.D., Rawlings, R.D., Alexander, J.M. 1990. Materials Science. 4th Edition. Chapman and Hall. London.

Agustinus, E.T.S., Sembiring, H., Saepuloh, A., Gurharyanto, Nurlela, I. 2007. Pembuatan Komposit Keramik Suhu Bakar Rendah Sebagai Bahan
Bangunan. Laporan Penelitian. Pusat Penelitian Geoteknologi LIPI. Bandung.

Ajie, G.N. 2008. Sintesis dan Karakteristik Keramik Struktural Alumina Pada Sintering Temperature Rendah Untuk Aplikasi Armor Facing. Tesis Sarjana ITB. Bandung.

German,R.M 1996. Sintering theory and practice. John Wiley \& Sons. Canada

Hartono, JMV. 1991. Teori Pembakaran.Informasi Teknologi Keramik dan gelas. Bahan Penelitian dan Pengembangan Industri. Balai Besar Industri Keramik. Bandung.

Mulder, M. 1996. Basic principles of membrane technology, $2^{\text {nd }}$ ed. Kluwer Academic Publisher. Dordrecht.

Sagala, M. 2000. Perubahan Fisika-Kimia dan Mineral Pada Pembakaran Lempung. Badan Penelitian dan Pengembangan Industri dan Perdagangan. Balai Besar Industri Keramik. Bandung.

Sembiring, A.D. 1990. Penguat dan Bahan Keramik untuk Konstruksi. Tesis Magister Universitas Indonesia (UI). Jakarta.

Surdia, T., Saito, S. 1985. Pengetahuan Bahan Teknik. PT Pradnya Paramita. Jakarta.

http://id.wikipedia.org/wiki/Limbah

http://id.wikipedia.org.wiki.Keramik,2009

http://aspdin.wifa.uni-leipzig.de/institut/lacer, 2008

Industri Keramik, Kasongan 2012.

Wikipedia bahasa Indonesia, ensiklopediabebas.htm. 